\title{
Characteristics of amino acid distributions in coastal waters off Korea Peninsula
}

\author{
B. $\mathrm{YEO}^{1}$, H. K. KWON ${ }^{1}$, H. HAN ${ }^{1}$, J. H. SEO ${ }^{1}$, G. $\mathrm{KIM}^{1 *}$
}

${ }^{1}$ Environmental \& Marine Biogeochemistry Laboratory, School of Earth \& Environmental Sciences, College of Natural Sciences, Seoul National University, Seoul 08826, Republic of Korea.

(booheon1995@gmail.com,kwon124@snu.ac.kr, hanheejun@snu.ac.kr, hyeongs2@naver.com,

* correspondence: gkim@snu.ac.kr )

The concentrations of dissolved organic carbon (DOC), D- and L-forms of total dissolved hydrolysable amino acids (D-AA, L-AA), fluorescent dissolved organic matter (FDOM), and inorganic/organic nutrients were observed in coastal waters in Jinhae Bay, Korea. In general, relatively higher concentrations of DOC, DON, D-AA, and L-AA were observed in the innermost stations of the bay, due to the influence of fresh water inputs. Based on the correlation analyses with salinities, the concentrations of DOC, terrestrial humic-like FDOM, and D-AA were almost conservative, but there was significant removal of inorganic/organic nutrients and a source of L-AA inside the bay. The concentrations of THAA, L-AA, DON, DOC were much higher than those observed in the surface waters of a marginal sea (East Sea) and the Pacific and Atlantic oceans. However, D-AA concentrations and $\mathrm{D} / \mathrm{L}$ ratios were lower than those in the East Sea and some regions in the major oceans, indicating that in-situ production of D-AA in coastal waters is insignificant. Thus, our study suggests that (1) amino acids in coastal waters are mostly bioavailable and (2) there are significant inputs and conservative mixing of terrestrial DAA in coastal waters. 